\title{
Hyperemesis Gravidarum
}

National Cancer Institute

\section{Source}

National Cancer Institute. Hyperemesis Gravidarum. NCI Thesaurus. Code C87084.

Severe, intractable vomiting during pregnancy (usually the first trimester) accompanied by dehydration, weight loss, and electrolyte imbalances. 